\title{
Efeito da qualidade das sementes sobre a formação de mudas de alface
}

\author{
Simone M. Franzin ${ }^{1}$; Nilson L. de Menezes; Danton C. Garcia; Osmar S. dos Santos
}

UFSM, Depto. Fitotecnia, Camobi, Santa Maria-RS, E-mail: smfranzin@yahoo.com.br; ${ }^{1}$ Aluna de doutorado em agronomia

\section{RESUMO}

Determinou-se o efeito da qualidade fisiológica das sementes sobre a formação de mudas de alface. Utilizaram-se dois lotes de sementes com diferentes níveis de qualidade inicial, das cultivares Regina e Vera, selecionados por meio dos testes de germinação, primeira contagem, envelhecimento acelerado, condutividade elétrica e emergência em "gerbox". Os efeitos dos níveis de qualidade sobre a produção de mudas foram avaliados por meio dos testes de índice de velocidade de emergência, número de folhas, altura da parte aérea, comprimento de raízes, massa úmida e seca das mudas e classificação do vigor das mudas. Utilizou-se o delineamento inteiramente casualizado, com os dados analisados pelo teste Tukey em 5\% de probabilidade. Houve efeito favorável na qualidade das sementes das cultivares Regina e Vera para a formação de mudas aos 20 dias após a semeadura. Concluiu-se que sementes de alta qualidade fisiológica produzem maior percentagem de mudas vigorosas, com maior número de folhas, maior altura da parte aérea e comprimento de raízes e maior massa aos 20 dias de cultivo.

Palavras-chave: Lactuca sativa, hortaliças, qualidade fisiológica.

\begin{abstract}
Effect of seed quality on lettuce seedlings development

The effect of the physiological quality of the seeds on lettuce seedlings was established. Two lots of lettuce seeds cv. Regina and Vera with different levels of initial quality were used. These lots were selected based upon germination tests: first score, fast aging, electrical conductivity and emergence in gerbox. The effects of the quality levels on the seedling production were evaluated through the parameters: speed rate emergence tests, number of leaves, height of the aerial part, root length, dry and wet mass of the seedlings and classification of the vitality of the seedlings. The experiment was carried out in a completely randomized design with four replications. Seed quality of the cultivars Regina and Vera have a positive effect on the formation of seedlings 20 days after sowing. High physiological quality seeds produce a higher percentage of vigorous seedlings, with a larger number of leaves, taller seedlings with longer roots and bigger mass at 20 days of cultivation.
\end{abstract}

Keywords: Lactuca Sativa, vegetables, physiological quality.

\section{(Recebido para publicação em 19 de dezembro de 2003 e aceito em 10 de janeiro de 2005)}

$\mathrm{O}$ conhecimento preciso do potencial fisiológico das sementes permite, principalmente para espécies onde há transplante de mudas, a obtenção de mudas de tamanho e qualidade uniformes, com reflexos no desenvolvimento das plantas e, possivelmente, na produção final (SOUZA, 1977; MARCOS FILHO, 2001). Portanto, a produção de mudas e de plantas sadias depende em grande parte da utilização de sementes de boa qualidade.

Sementes de alto potencial fisiológico são essenciais para que ocorra germinação rápida e uniforme (MARCOS FILHO, 1999), devido à sua influência no desempenho inicial das plantas. Esse efeito pode ser reduzido com a evolução do crescimento, afetando ou não a produção, dependendo do órgão da planta explorado comercialmente e do estádio em que é efetuada a colheita (CARVALHO; NAKAGAWA, 2000). Sementes consideradas vigorosas são mais efetivas na mobilização e utilização de suas reservas energéticas (VIEIRA; CARVALHO 1994), como conseqüência, há maior capacidade metabólica, resultando em maior massa inicial (DAN et al., 1987).
A produção de mudas de hortaliças constitui uma das etapas mais importantes do sistema produtivo. Dela depende o desempenho final das plantas, seja em relação ao aspecto nutricional ou do tempo necessário para a produção e, consequentemente, do número de ciclos produtivos por ano (CARMELLO, 1995). Portanto, utiliza-se novas técnicas na produção de mudas de hortaliças, como o sistema de semeadura em bandejas (MARCOS FILHO, 2001).

A alface é exemplo de cultura que vem obtendo cada vez mais ênfase em cultivos intensivos (ZITO et al., 1994). A influência da qualidade das sementes na produção de mudas e plantas tem sido verificada em estudos como os realizados por Souza (1977) com sementes de trigo, onde o vigor foi fator determinante da qualidade das sementes e na produção final.

Em cebola, Piana et al. (1995) verificaram que há relação direta entre o potencial fisiológico das sementes, a emergência das plântulas em campo e o desempenho das mudas. Contudo, nem sempre a qualidade das sementes detec- tada em laboratório, reflete seu potencial em campo (CALIARI; MARCOS FILHO, 1990). Em experimentos realizados com sementes de cebola cultivar Aurora, Rodo (2002) verificou que houve relação entre o potencial fisiológico dos lotes de sementes e o desempenho da plantas.

Considerando que a qualidade fisiológica das sementes pode afetar a produção de mudas e o posterior desenvolvimento das plantas, procurou-se determinar neste trabalho o efeito da qualidade fisiológica das sementes sobre a formação de mudas de alface.

\section{MATERIAL E MÉTODOS}

O experimento foi desenvolvido em laboratório de sementes e de hidroponia da UFSM. Foram utilizados seis lotes de sementes de alface (Lactuca sativa L.) cv. Regina e seis lotes da cv. Vera. De cada cultivar, classificaram-se dois lotes de diferentes níveis de qualidade inicial, com base na germinação e vigor das sementes. O teste de germinação foi realizado em caixas plásticas do tipo "gerbox", conforme preconizado por 
Tabela 1. Comparação das médias de germinação $(\mathrm{G})$ e de vigor através dos testes de primeira contagem (PC), envelhecimento acelerado (EA) e emergência em gerbox 48 h (EG), em \%, em sementes de alface cv. Regina e Vera. Santa Maria, UFSM, 2002.

\begin{tabular}{|c|c|c|c|c|c|c|c|c|c|}
\hline \multirow{2}{*}{ Lotes } & \multirow{2}{*}{ Vigor } & \multicolumn{4}{|c|}{ Regina } & \multicolumn{4}{|c|}{ Vera } \\
\hline & & $\mathbf{G}$ & PC & EA & EG $48 \mathrm{~h}$ & G & $P C$ & EA & EG $48 \mathrm{~h}$ \\
\hline 1 & Alto & $88 a^{*}$ & $88 a$ & $92 a$ & $81 a$ & $90 a^{*}$ & $84 a$ & $84 a$ & $51 a$ \\
\hline \multirow[t]{2}{*}{2} & Médio & $80 a$ & $64 \mathrm{~b}$ & $52 b$ & $29 \mathrm{~b}$ & $80 \mathrm{~b}$ & $73 b$ & $71 \mathrm{~b}$ & $46 a$ \\
\hline & CV (\%) & 7,1 & 5,8 & 5,7 & 11,6 & 7,1 & 5,8 & 5,7 & 11,6 \\
\hline
\end{tabular}

*Médias seguidas pela mesma letra na coluna, não diferem entre si pelo teste Tukey em 5\% de probabilidade de erro.

Brasil (1992). Os seguintes testes de vigor foram empregados para definir a qualidade dos lotes: primeira contagem, realizada no quarto dia após a semeadura sobre papel filtro, juntamente com o teste de germinação; envelhecimento acelerado realizado em mini-câmara "gerbox", sob $41^{\circ} \mathrm{C}$, por $72 \mathrm{~h}$ e $100 \%$ de umidade relativa do ar; emergência em "gerbox", com a contagem das plântulas normais emersas após a semeadura, em caixas plásticas contendo substrato organo-mineral (Plant Max $\mathrm{HA}^{\mathrm{O}}$ ), mantidas em germinador a $25^{\circ} \mathrm{C}$, por $48 \mathrm{~h}$, como descrito por Franzin (2003).

Após a seleção de um lote de alta e outro de média qualidade, de cada cultivar, as sementes foram colocadas em bandejas de isopor com substrato organo-mineral, que foram mantidas em tanques rasos do tipo piscina com $10 \mathrm{~cm}$ de profundidade, contendo solução nutritiva proposta por Castellane e Araújo (1995).

Os seguintes testes foram aplicados para verificar os efeitos dos níveis de qualidade inicial das sementes sobre a formação de mudas de alface:

Índice de velocidade de emergência (IVE)

Utilizou-se quatro amostras de 50 sementes, com semeadura em bandejas de isopor, contendo substrato organomineral e mantidas em "piscina hidropônica" contendo solução nutritiva diluída a $25 \%$, conforme proposto por Castelane e Araujo (1995), efetuandose contagem diária das plântulas emersas. Para cada repetição, foi calculado o índice de velocidade de emergência, somando-se o número de plântulas emersas a cada dia, que foi dividido pelo respectivo número de dias transcorridos a partir da semeadura. Esse procedimen- to foi adotado até se obter número constante de plântulas emersas, conforme procedimento proposto por Maguire (1962).

\section{Número de folhas (NF)}

Utilizou-se quatro amostras de 10 mudas para cada lote de sementes, avaliando-se o número de folhas formadas em cada muda, após atingirem a altura mínima de $6 \mathrm{~cm}$. Os resultados expressaram o número médio de folhas produzidas por muda.

\section{Altura da parte aérea das mudas (APA)}

Foram utilizadas quatro amostras de 10 mudas para cada lote de sementes, retiradas no momento de transplante aos 20 dias de cultivo. A parte aérea das mudas, porção acima do nó radicular, foi medida com auxílio de régua milimetrada, computando-se os resultados médios de cada repetição em $\mathrm{cm} /$ muda.

\section{(CR)}

Comprimento de raízes das mudas

Foram utilizadas quatro amostras de 10 mudas para cada lote de sementes, retiradas no momento do transplante aos 20 dias de cultivo. As raízes das mudas, porção abaixo do nó radicular, foram medidas com auxílio de régua milimetrada, computando-se os resultados médios de cada repetição em cm/ muda.

\section{Massa úmida e massa seca das} mudas (MU e MS)

As mudas selecionadas para o teste de comprimento de raízes, logo após as determinações da altura da parte aérea e comprimento das raízes, foram pesadas em balança analítica de precisão (0,001 g), obtendo-se a massa úmida das mudas de cada repetição, com resultados expressos em mg/muda. Para a ob- tenção da massa seca, as mudas de cada repetição foram inseridas em saco de papel e mantidas em estufa regulada a $60^{\circ} \mathrm{C}$, até atingirem massa constante. Após serem retiradas da estufa e resfriadas, foram pesadas em balança analítica, obtendo-se a massa seca das mudas, com os resultados expressos em $\mathrm{mg}$ / muda.

\section{Classificação do vigor das mudas (CVM)}

Aos 20 dias após a semeadura, utilizaram-se quatro amostras de 10 mudas para cada lote de sementes, classificando-as em mudas normais em fortes (vigorosas) ou fracas (pouco vigorosas). As mudas consideradas morfologicamente perfeitas, sem lesões e com altura superior a $10 \mathrm{~cm}$ e com presença de quatro ou mais folhas foram consideradas fortes, enquanto aquelas que apresentaram algum problema na sua altura, altura inferior a $10 \mathrm{~cm}$ e número de folhas inferior a quatro ou cinco, foram consideradas fracas.

$\mathrm{Na}$ análise estatística empregou-se o delineamento inteiramente casualisado, com quatro repetições, em esquema fatorial $2 \times 2$ (duas cultivares e dois lotes) e os dados obtidos em cada teste foram analisados por meio de análise de variância, com comparação de médias pelo teste Tukey em 5\% de probabilidade.

\section{RESULTADOS E DISCUSSÃO}

A Tabela 1 contém as caracterizações iniciais dos lotes de sementes de alface das cultivares Regina e Vera. $\mathrm{O}$ lote 1, por apresentar alta germinação e vigor foi classificado como de alta qualidade. O lote 2, ainda passível de uso como sementes, apresentou menor germinação e vigor que o lote 1e foi classificado como de média qualidade.

Na Tabela 2 são apresentados os resultados de índice de velocidade de emergência (IVE) referentes às cultivares Regina e Vera. Para a cultivar Regina, o lote considerado de alta qualidade apresentou o maior índice de velocidade de emergência das plântulas. Esse fato era esperado, visto que sementes mais vigorosas, por apresentarem maior estabilidade em suas estruturas, iniciam o processo germinativo antes que aque- 
las menos vigorosas. Além disso, a maior emergência de plântulas em lotes mais vigorosos, justifica a preferência na utilização de sementes de alta qualidade fisiológica, pois estas permitirão a ocorrência de germinação rápida e uniforme, mesmo sob ampla variação das condições de ambiente (MARCOS FILHO, 2001).

Para a cultivar Vera não se observou diferença significativa entre os lotes de diferentes níveis de vigor quanto ao IVE, embora tenha-se observado uma pequena tendência dos lotes de maior nível de vigor apresentarem maior IVE (Tabela 2). Rosseto et al. (1997), observaram elevada relação entre emergência de plântulas e qualidade fisiológica das sementes, ainda que os lotes de médio vigor, freqüentemente tenham a velocidade de emergência de plântulas reduzida.

O número de folhas produzidas por muda na cultivar Regina (Tabela 3 ) foi significativamente superior no lote de maior vigor. Tal fato, deveu-se à qualidade das sementes, que estabeleceu, no início da formação da planta, maior velocidade de emergência e, consequentemente, formação mais rápida de folhas. Essas diferenças, após algum tempo, geralmente, desaparecem, pois é esperado que o vigor das sementes influencie visivelmente o desempenho inicial das plantas, e também, porque o número final de folhas refere-se a uma característica varietal.

Para altura da parte aérea das mudas observou-se diferenças significativas entre os lotes estudados para a cultivar Regina. Na Tabela 3 observa-se que ocorreu maior altura das mudas para o lote de alta qualidade, visto que sementes de alto vigor mobilizam e utilizam mais rapidamente as reservas energéticas, importantes para o início do

Tabela 2. Índice de velocidade de emergência (IVE) em bandeja de sementes de alface cv. Regina e Vera. Santa Maria, UFSM, 2002.

\begin{tabular}{lcc}
\hline \multirow{2}{*}{ Níveis de vigor das sementes } & \multicolumn{2}{c}{ IVE } \\
\cline { 2 - 3 } & Regina & Vera \\
\hline Alto & $7 a^{*}$ & $5 a$ \\
Médio & $5 \mathrm{~b}$ & $4 \mathrm{a}$ \\
\hline CV $(\%)$ & 6,5 & 4,5 \\
\hline
\end{tabular}

*Médias seguidas pela mesma letra na coluna, não diferem entre si pelo teste Tukey em 5\% de probabilidade de erro.

processo de germinação (DAN et al., 1987; VIEIRA; CARVALHO, 1994), por conseguinte, apresentam maior crescimento inicial e desenvolvimento. Isso justifica os melhores resultados para o lote considerado de alta qualidade. Estudos realizados em cebola (RODO, 2002) também evidenciaram diferenças na produção em relação à altura da parte aérea das mudas, demonstrando a influência da qualidade fisiológica das sementes sobre a qialidade das mudas de cebola. Souza (1977) trabalhando com sementes de trigo também destaca a ocorrência de maior desenvolvimento para lotes mais vigorosos, indicando, com isso, a influência do vigor da semente na produção.

O comprimento de raiz vem sendo sugerido como parâmetro útil na a avaliação da qualidade de sementes em alface (MCDONALD, 2001; SAKO et al. 2001). Porém, o método de medição manual é de difícil execução e muitas vezes afeta os resultados.

Assim como nos demais testes, a avaliação da massa úmida confirmou que as sementes com maior qualidade produziram mudas mais vigorosas (Tabela 3). A maior massa das mudas foi produzida pelas sementes de melhor qualidade, o que se deve, provavelmente, à maior mobilização e utilização de suas reservas (DAN et al., 1987; VIEIRA; CARVALHO, 1994).
Os maiores valores de massa seca das mudas também foram detectados no lote mais vigoroso, embora esse teste apresente, algumas vezes, dificuldade na diferenciação de lotes, devido às deficiências na sua metodologia para avaliação de sementes pequenas. Observou-se para a cultivar Regina, maiores valores de massa seca para o lote de maior qualidade inicial. Sementes mais vigorosas têm maior probabilidade de sucesso na germinação e na formação de plântulas, caso o ambiente na época de semeadura seja menos favorável (MARCOS FILHO, 1999). Além disso, essas sementes podem apresentar maiores quantidades e mobilização de reservas, o que proporciona maior incremento de massa no início do desenvolvimento da planta.

A avaliação da cultivar Vera revelou resultados similares para os testes utilizados em ambos os níveis de vigor (Tabela 3). A dificuldade de classificação dos lotes em alta e média qualidade, devido à homogeneidade dos mesmos para esta cultivar, pode ter decorrido da falta de estratificação entre os lotes. Quanto à variável número de folhas, observou-se maiores valores absolutos nas mudas provenientes das sementes de alta qualidade, embora não tenha havido diferenças significativas entre os lotes.

$\mathrm{Na}$ altura da parte aérea das mudas da cultivar Vera não houve diferença en-

Tabela 3. Número de folhas (NF), altura da parte aérea (APA em cm), comprimento das raízes (CR em $\mathrm{cm}$ ), massa úmida (MU em mg) e massa seca (MS em mg) de mudas de alface obtidas a partir das sementes de vigor alto e médio das cultivares Regina e Vera. Santa Maria, UFSM, 2002.

\begin{tabular}{|c|c|c|c|c|c|c|c|c|c|c|}
\hline \multirow{2}{*}{ Vigor } & \multicolumn{5}{|c|}{ Regina } & \multicolumn{5}{|c|}{ Vera } \\
\hline & NF & APA & CR & MU & MS & NF & APA & CR & MU & MS \\
\hline Alto & $8 a^{*}$ & $8,8 a$ & $12,3 a$ & $164 a$ & $79 a$ & $6 a^{*}$ & $10,4 a$ & $14,8 a$ & $148 a$ & $85 a$ \\
\hline Médio & $7 b$ & $7,9 \mathrm{~b}$ & $11,9 a$ & $122 b$ & $59 b$ & $5 a$ & $9,2 a$ & $11,0 b$ & $158 a$ & $78 a$ \\
\hline CV (\%) & 6,0 & 2,2 & 8,7 & 5,7 & 2,4 & 8,3 & 14,7 & 313,3 & 11,1 & 13,0 \\
\hline
\end{tabular}

*Médias seguidas pela mesma letra na coluna, não diferem entre si pelo teste Tukey em $5 \%$ de probabilidade de erro. 


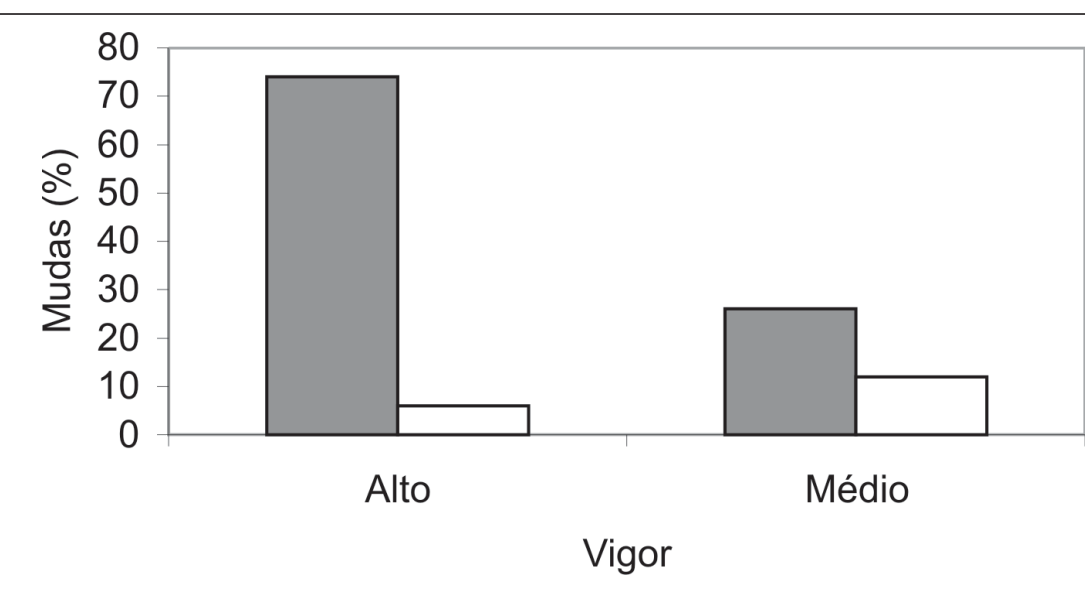

(a) cultivar Regina

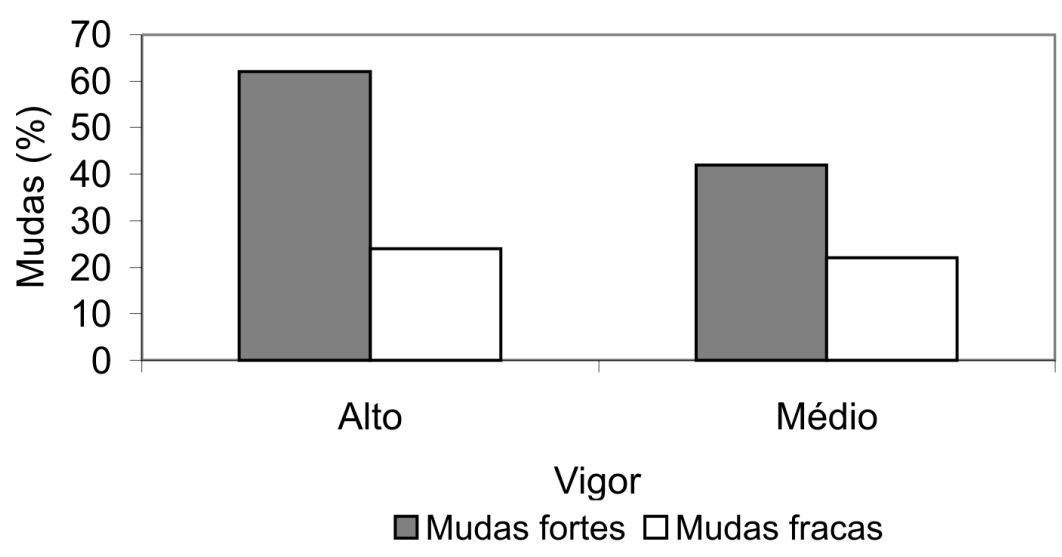

(b) cultivar Vera

Figura 1. Qualidade das mudas de alface, cultivar Regina (a) e Vera (b), provenientes de lotes de sementes de alto e médio vigor. Santa Maria, UFSM, 2002.

tre lotes. No entanto, os maiores valores absolutos de altura foram observados nas mudas provenientes do lote de maior qualidade. A semelhança entre os resultados encontrados na altura das mudas, pode estar vinculada à dificuldade de classificação da qualidade inicial, em razão da homogeneidade nas características dos lotes desta cultivar. Em sementes de cebola, cultivar Aurora, Rodo (2002) verificou em apenas um dos lotes de sementes associação entre os testes de vigor com a altura das mudas.

Diferentemente do que ocorreu com Regina, os lotes revelaram diferenças significativas no comprimento das raízes da cultivar Vera, sendo que o lote de maior qualidade inicial apresentou valor significativamente superior ao encontrado no lote de média qualidade. A eficiência do teste de comprimento de raízes na avaliação das mudas de alface da cv. Vera, indica que embora haja di- gica das sementes de alface. Embora tenha apresentado dificuldade de separação de lotes nesta cultivar, esses testes foram altamente sensíveis para a avaliação da cv. Regina, mais uma vez indicando o efeito das diferenças varietais na avaliação das sementes. Dificuldade de estratificação de lotes pelo teste de massa seca, foi constada também por Rodo (2002) com mudas de cebola, onde a autora considerou insuficientes os resultados observados para estabelecer relação entre o potencial fisiológico das sementes e o desempenho das plantas.

$\mathrm{Na}$ Figura 1 podem ser visualizados os efeitos da qualidade inicial das sementes de alface em relação a formação de mudas normais vigorosas e pouco vigorosas. Para a cultivar Regina (Figura 1a), observou-se que o maior número de mudas foi produzido pelo lote de maior qualidade, sendo a percentagem de mudas vigorosas produzidas por esse lote superior dentro e entre os níveis de vigor, além de ocorrer baixa produção de mudas consideradas pouco vigorosas. Esses resultados indicam que lotes de sementes com alta qualidade são mais resistentes às condições ambientais adversas, possivelmente, pelo menor grau de deterioração das sementes, como descreveu Souza (1977), em trabalho com trigo, em que a qualidade das sementes afetou diretamente a produção.

O lote de qualidade média da cultivar Regina apresentou aumento na percentagem de mudas pouco vigorosas, com redução na produção de mudas vigorosas. Lotes de menor vigor encontram-se em grau mais elevado de deterioração, promovendo a formação de mudas menos desenvolvidas e como conseqüência, anormais. Esse fato foi verificado nos estudos com sementes de trigo, em que lotes menos vigorosos promoveram formação de maior número de plântulas anormais (SOUZA, 1977). A formação de mudas com tamanho e qualidade uniformes, assim como, o estabelecimento do estande, estão relacionados com a utilização de sementes capazes de germinar com maior uniformidade e rapidez (MARCOS FILHO, 2001), o que decorre do alto potencial fisiológico das sementes.

Os resultados da classificação da qualidade das mudas da cultivar Vera 
(Figura 1b), indicaram que houve formação de menor número de mudas em relação a Regina, provavelmente pelo fato de Vera ser menos adaptada ao clima de verão, além das diferenças varietais entre os genótipos. Observouse que o lote de maior qualidade produziu maior percentagem de mudas vigorosas, com acentuada formação de mudas pouco vigorosas, enquanto o lote de média qualidade teve menor percentagem de mudas vigorosas.

Embora a cultivar Vera tenha apresentado maior percentagem de emergência de plântulas, a formação de mudas mais vigorosas ocorreu na cultivar Regina. Isto indica que o potencial genético desta cultivar adaptada às condições de verão, resistindo melhor a altas temperaturas que ocorreram na estufa, é também um fator essencial na avaliação da qualidade fisiológica das sementes.

De maneira geral, foi possível constatar que a qualidade das sementes exerceu influência na formação das mudas de alface e que lotes de sementes com maior qualidade inicial, detectados pelos testes de germinação e vigor realizados em laboratório, produzem respostas melhores às condições do ambiente. No entanto, tais fatores dependem também do genótipo da cultivar estudada.

\section{LITERATURA CITADA}

BRASIL. Ministério da Agricultura do Abastecimento e da Reforma Agrária/ SNDA. Regras para Análise de Sementes. Brasília, 1992. 365 p.

CALLIARI, M.F.; MARCOS FILHO, J. Comparação entre métodos para avaliação da qualidade fisiológica de sementes de ervilha (Pisum sativum L.). Revista Brasileira de Sementes, Brasília, v.12, n.3, p.52-75, 1990.

CARMELLO, Q.A.C. Nutrição e adubação de mudas hortícolas. In: MINAMI, K. Produção de mudas de alta qualidade em horticultura. São Paulo: T.A. Queiroz, 1995, p.27-37.

CARVALHO, N.M.; NAKAGAWA, J. Sementes - ciência, tecnologia e produção. 4 ed. Jaboticabal, FCA/FUEP, 2000, 588 p.

CASTELLANE, D.P.; ARAÚJO, J.A.C. Cultivo sem Solo - hidroponia, Jaboticabal: UNESP, 43 p. 1995.

DAN, E.L.; MELLO, V.D.C.; WETZEL, C.T.; POPINIGIS, F.; ZONTA, E.P. Transferência de matéria seca como modo de avaliação do vigor de sementes de soja. Revista Brasileira de Sementes, Brasília, v.9, n.3, p.45-55, 1987.

McDONALD, M.B. Imagem de plântulas. Seed News. Pelotas, n.6, p.18, 2001.

MAGUIRE. J.D. Spead of germination-aid in selection and evaluation for seedling emergence and vigour. Crop Science. Madison, v.2, n.1, p.176-177, 1962.

MARCOS FILHO, J. Testes de Vigor: Importância e Utilização. In: KRZYZANOWSKI, F.C.; VIEIRA, R.D. e FRANÇA NETO, J.B. Vigor de Sementes: conceitos e testes. Londrina: ABRATES, Comitê de Vigor de Sementes, 218 p. 1999.
MARCOS FILHO, J. Pesquisa sobre vigor de sementes em hortaliças. Informativo ABRATES, Brasília, v.11, n.3, p.63-75, 2001.

PIANA, Z.; TILLMANN, M.A.A.; MINAMI, K. Avaliação fisiológica de sementes de cebola e sua relação com a produção de mudas vigorosas. Revista Brasileira de Sementes. Brasília, v.17, n.2, p.149-153, 1995.

RODO, A.B. Avaliação do potencial fisiológico de sementes de cebola e sua relação com o desempenho das plantas em campo. 2002, $123 \mathrm{f}$ (Tese doutorado) - ESALQ, USP, Piracicaba.

ROSSETTO, C.A.V.; NOVEMBRE, A.D.; DAL, C.; MARCOS FILHO J.; SILVA, W.R.; NAKAGAWA, J. Efeito da disponibilidade hídrica do substrato, da qualidade fisiológica e do teor de água inicial das sementes de soja no processo de germinação. Scientia Agricola, Piracicaba, v.54, n.1/2, p.97-105, 1997.

SGANZERLA, E. Nova Agricultura - a fascinante arte de cultivar com plásticos. 6 ed., Guaíba: Agropecuária, 1997. p.187-192.

SOUZA, F.C.A. $O$ vigor da semente de trigo e a sua influência na produção. Trigo e soja, Porto Alegre, v.22, n.5-7, 1977.

VIEIRA, R.D.; CARVALHO N.M. Testes de vigor em sementes. Jaboticabal: FUNEP, 1994. 164 $\mathrm{p}$.

ZITO, R.K.; FRONZA, V.; MARINEZ, H.E.P.; PEREIRA, P.R.G; FONTES, P.C.R. Fontes de nutrientes, relações nitrato: amônio e molibdênio, em alface (Lactuca sativa L.) produzida em meio hidropônico. Revista Ceres. Viçosa, v.41, n.236, p.419-430, 1994. 